\title{
Morfofisiologia da inervação do diafragma de ovinos ${ }^{1}$
}

\author{
Ana E.F. de Almeida ${ }^{2}$, Cristiane V. Wenceslau², Dulcinéa G. Teixeira², Karla \\ P.C. Araújo ${ }^{2}$, Adriana C. Morini², João C. Morini Jr², Carlos E. Ambrósio2*, \\ Maria A. Miglino² e Irvênia L.S. Prada²
}

\begin{abstract}
Almeida A.E., Wenceslau C.V., Teixeira D.G., Araújo K.P.C., Morini A.C., Morini Jr J.C., Ambrósio C.E., Miglino M.A. \& Prada I.L.S. 2008. [Morphophysiology of diaphragm innervation in sheep.] Morfofisiologia da inervação do diafragma de ovinos. Pesquisa Veterinária Brasileira 28(9):399-409. Setor de Anatomia dos Animais Domésticos e Silvestres, Faculdade de Medicina Veterinária e Zootecnia, Universidade de São Paulo, Av. Prof. Dr. Orlando Marques de Paiva 87, Cidade Universitária, São Paulo, SP 05508-900, Brazil. E-mail: ceambrosio@usp.br

Thirty diaphragms of sheep of Santa Inês breed were studied regarding their origin, division and arrangement of the right and left phrenic nerves (Fde), and the participation of other nerves in the innervation of the diaphragm. By fixing and dissecting pieces, it was found that phrenic nerves $(F)$ frequently come from the ventral branches of the $5^{\text {th }}$ $(\mathrm{C} 5)$ and $6^{\text {th }}(\mathrm{C} 6)$ cervical spinal nerves (Ec), at right $(46.67 \%)$ and at left $(43.33 \%)$. The F often form a lumbocostal trunk, sternal branches at right $(40.00 \%)$ and lumbar, costal and esternal branches at left $(36.68 \%)$. The lumbar branches of $F$ innervate frequently at left $(96.67 \%)$ the homolateral pillar of the diaphragma, and at right $(50.00 \%)$ they give fillets to Vena cava caudalis. The costal branches of the F innervate at left $(90.00 \%)$ and at right $(76.66 \%)$ the dorsal and ventral regions of the pars costalis. The sternal branches of the $\mathrm{F}$ innervate at right $(100.00 \%)$ and at left $(83.33 \%)$ the pars sternalis and the ventral region of the pars costalis at the same side. The intercostal nerves (VII to XII pairs, $63.33 \%$ ) contribute to innervate the diaphragm of Santa Inês sheep.
\end{abstract}

INDEX TERMS: Anatomy; phrenic nerves, sheep, diaphragma, nervous system.

RESUMO.- Foram estudados em 30 diafragmas de ovinos da raça Santa Inês, a origem, a divisão e a distribuição dos nervos frênicos direito e esquerdo (Fde) e a participação de outros nervos na inervação do diafragma. Mediante fixação e dissecação das peças foi observado que os nervos frênicos $(F)$ originam-se a partir dos ramos ventrais do $5^{\circ}(\mathrm{C} 5)$ e $6^{\circ}(\mathrm{C} 6)$ nervos espinhais cervicais (Ec) tanto à direita $(46,67 \%)$ como à esquerda $(43,33 \%)$. Os $\mathrm{F}$ finalizam em tronco lombocostal e ramo esternal à direita $(40,00 \%)$ e em ramo lombar, costal e esternal à esquerda $(36,68 \%)$. Os ramos lombares dos $\mathrm{F}$ inervam à

\footnotetext{
${ }^{1}$ Recebido em 3 de novembro de 2007.

Aceito para publicação em 28 de agosto de 2008.

2 Setor de Anatomia dos Animais Domésticos e Silvestres, Departamento de Cirurgia, Faculdade de Medicina Veterinária e Zootecnia, Universidade de São Paulo, Av. Prof. Dr. Orlando Marques de Paiva 87, Cidade Universitária, São Paulo, SP 05508-900, Brasil. *Autor para correspondência: ceambrosio@usp.br
}

esquerda $(96,67 \%)$ o pilar homolateral do diafragma e, à direita $(50,00 \%)$ fornecem filetes à veia caudal. Os ramos costais dos $\mathrm{F}$ ramificam à esquerda $(90,00 \%)$ e à direita $(76,67 \%)$ as regiões dorsal e ventral da pars costalis. Os ramos esternais dos $F$ inervam à direita $(100,00 \%)$ e à esquerda (83,33\%) a pars sternalis e a região ventral da pars costalis do mesmo lado. Os nervos intercostais (VIII ao XII pares, $63,33 \%$ ) contribuem na inervação do diafragma de ovinos da raça Santa Inês.

TERMOS DE INDEXAÇÃO: Nervo frênico, ovinos, diafragma, sistema nervoso.

\section{INTRODUÇÃO}

A ovinocultura é uma atividade econômica em franca expansão, presente em áreas sob as mais diversas características climáticas, sendo amplamente exploradas graças à rusticidade e à adaptação ao meio ambiente. Tal fato possibilitou o surgimento de algumas raças, a exemplo da Santa Inês, formada a partir da raça Morada Nova 
brasileira com ovinos da raça Italiana Bergamância (Machado 1999, Leite 2000).

Em relação às descrições morfológicas do sistema nervoso autônomo em ovinos especificamente, estas são escassas na literatura, vistos como exemplo, a morfologia e topografia dos nervos glossofaríngeos e vago descritos por Farias et al. (2007). Sendo assim, dando continuidade a estes estudos, visamos estudar a inervação diafragmática nesta espécie.

O diafragma, ao dispor, nos mamíferos, entre as cavidades do tórax e do abdome, apresenta duas regiões: uma central tendínea e uma periférica muscular, na qual se distinguem, em cada antímero, as porções lombar, costal e esternal. O mesmo se apresenta sob a forma de uma cúpula convexa (Getty 1986, König \& Liebich 2004).

O músculo diafragmático é complexo quanto ao modo de sua formação e à sua estrutura, posto que se desenvolve a partir de quatro fontes, segundo Arey (1964): do septum transversum, seu principal componente ventral; das membranas pleuroperitoneais e da parede corpórea, suas partes dorsolaterais e ventrolaterais, respectivamente; do mesoesôfago, sua parte mediodorsal.

Os autores clássicos como Zimmerl (1909), Andrei (1928), Bertelli (1933), Conde (1957) e Dyce et al. (2004) relatam que o nervo frênico $(F)$ constitui a principal fonte de inervação motora do diafragma, sendo que uma lesão nesse nervo resulta quase sempre em morte por asfixia devido a paralisia desse órgão (Riet-Correa et al. 2002). Para Cavalíe (1898), os nervos intercostais também contribuem com fibras motoras para essa inervação para Dyce et al. (2004) nos carnívoros as fibras sensitivas do músculo diafragma são suplementadas por ramos emitidos pelos nervos intercostais.

Zimmerl (1909, 1930), Lesbre (1923), Ellenberger \& Baum (1932), Chauveau et al. (1950), Dobberstein \& Hoffman (1964), Schwarze \& Schroder (1972), Nickel et al. (1977) e Dyce et al. (2004) descrevem os F como emergentes do $5^{\circ}$, $6^{\circ}$ e $7^{\circ}$ nervos cervicais, sendo que suas raízes correm junto ao músculo escaleno em direção ao tórax, unindo-se em uma só estrutura que se dirige ao diafragma para formar sua inervação motora. Quanto à divisão dos F, os autores Zimmerl (1909), Lesbre (1923), Ellenberger \& Baum (1932) e Gonzáles y Garcia \& González Alvarez (1949), relatam que os nervos chegam ao centro frênico e se distribuem à porção carnosa depois de sucessivas divisões.

Moreira et al. (2007) ao estudar a ramificação e distribuição dos nervos frênicos no músculo diafragma do gato doméstico constatou inúmeras semelhanças entre a espécie alvo de seu estudo, e o sagüi e o cão principalmente quanto a sua ramificação, em relação a distribuição. $O$ gato possui conexão de fibras entre os nervos frênicos contralaterais, e fora esse fato, assemelha-se muito ao sagüi.

Chou \& Davenport (2005) afirmaram que a ativação dos nervos frênicos aferentes na medula espinhal dorsal cervical pode estar envolvida em informações das projeções centrais nos músculos aferentes respiratórios.
Teve-se como propósito descrever a inervação do diafragma, contribuindo para a escolha de locais de abordagem clínica e cirúrgica; objetivando determinar as raízes nervosas que compõem os $F$ na região cervical da coluna vertebral, bem como seus eventuais pontos de união; permitindo alicerçar pesquisas correlatas em Anatomia, Fisiologia e Embriologia embasando o estabelecimento de eventuais diferenças raciais.

\section{MATERIAL E MÉTODOS}

Foram utilizados 30 ovinos da raça Santa Inês, sendo 9 fêmeas e 21 machos, com idades de 1-3 anos, obtidos do município de Ibirá, Bahia, e de frigoríficos do Estado.

Após abate, os animais foram conduzidos ao laboratório de anatomia da Faculdade de Medicina Veterinária da Universidade Federal da Bahia os quais, foram fixados em solução de paraformaldeído a $10 \%$. Procedeu-se à abertura da cavidade torácica através da secção dos antímeros e remoção do gradil torácico (entre $1^{\circ}$ e $7^{\circ}$ par de costelas), seguida da retirada dos pulmões e localização dos $\mathrm{F}$ e dos ramos ventrais dos nervos espinhais cervicais (Ec).

Para a identificação dos locais de origem na região cervical, e a união dos Ramos ventrais dos Ec, realizou-se o afastamento dos músculos da região cervical. Uma vez visualizados, os nervos e suas raízes formadoras, seccionou-se a peça, separando o pescoço do tronco e o tórax do abdome, reduzindo a peça em um pequeno segmento da porção lombar. No trajeto dos nervos lombares foi observado se havia alcance dos mesmos a pars lumbalis, seguido da retirada do segmento lombar junto às articulações costovertebrais.

Os espaços intercostais a partir da $8^{\underline{a}}$ costela foram dissecados para averiguar se estes dirigiam-se em direção ao diafragma. O músculo diafragma com suas inserções costais e esternais foi lavado em água corrente e imerso em solução aquosa de paraformoldeído a 10\%. Com auxílio de uma lupa bi-focal LP23II (1,8-2,3x), o diafragma foi dissecado, sendo abordado em sua face torácica.

$\mathrm{Na}$ descrição dos resultados foi adotada a Nomenclatura Anatômica Veterinaria (International Committe on Veterinary Gross Anatomical Nomenclature 1994) a qual trata as porções carnosa do diafragma por expressões: pars lumbalis, pars costalis e pars sternalis. Com base neste procedimento e obedecendo a natural disposição dos ramos terminais dos nervos, adotamos a denominação efetuada por Amorim Júnior (1988).

Convencionamos dividir a pars costalis em regiões dorsal e ventral traçando uma linha imaginária tangente à terminação ventral dos pilares diafragmáticos. Quanto à porção tendinéa, consideramos três regiões: os folíolos dorsal direito, dorsal esquerdo e ventral. Em relação ao critério para o estabelecimento de limite entre pars sternalis e pars costalis observamos que, entre elas existe uma separação por um espaço sem reforço muscular.

Foram realizados desenhos esquemáticos e fotodocumentação das raízes cervicais formadoras dos $\mathrm{F}$ e de sua distribuição. Para melhor visualização, os nervos receberam pintura com tinta Acrilex ${ }^{\circledR}$ na cor amarela.

Alguns dados dos resultados foram tratados estatisticamente. Ressaltamos que a distribuição da variável nas diversas classes apresenta número menor do que o recomendado para o teste do $\chi^{2}$, levando a uma possível ocorrência de viés. 


\section{RESULTADOS}

\section{Origem dos nervos frênicos}

Os $\mathrm{F}$ originam-se a partir de uma, duas, ou três raízes e de acordo com o número de raízes formadoras, os quais são divididos em tipos I, II e III.

\section{Nervo frênico direito}

O nervo frênico direito $(\mathrm{Fd})$ em $73,33 \%$ das oportunidades origina-se por duas raízes (tipo II). Apresenta arranjos variados sendo que em $36,67 \%$ as raízes formadoras procedem dos ramos ventrais do $5^{\circ}$ e $6^{\circ} \mathrm{Ec}$, sendo que cada um contribui com um único filete nervoso (Fig.1A). Enquanto que em $20,00 \%$ origina-se a partir de duas raízes procedentes dos ramos ventrais do $6^{\circ}$ e $7^{\circ}$ Ec, contribuindo cada ramo com um único filete nervoso (Fig.1B). Em 13,33\% o Fd é constituído por duas raízes procedentes dos ramos ventrais do $5^{\circ}$ e $6^{\circ} \mathrm{Ec}$, sendo que C6 exibe dois filetes nervosos (Fig.1C).

Em $26,67 \%$ o Fd é originado por três raízes (tipo III) e apresenta dois arranjos: em $20,00 \%$, as raízes formadoras do Fd procedem dos ramos ventrais do 5, 6을 $7^{\circ}$, com cada nervo cervical fornecendo um único filete nervoso (Fig.1D); mostra-se procedente dos ramos ventrais do $5^{\circ}, 6^{\circ}$ e $7^{\circ} \mathrm{Ec}$, com $\mathrm{C} 6$ contribuindo com dois filetes nervosos em 6,67\% (Fig.1E).

O tipo I (uma raiz) não é encontrado em nenhuma das peças observadas.

\section{Níveis de origem da união dos filetes nervosos for-} madores do nervo frênico direito

A união dos filetes nervosos do $\mathrm{Fd}$ proveniente dos ramos ventrais do $5^{\circ}$ e $6^{\circ}$ ou do $6^{\circ}$ e $7^{\circ}$ Ec, cada um contribuí com um único filete nervoso (Fig.1 A e 1B). Estas uniões ocorreram aos níveis da $1^{\text {a }}$ costela em $43,33 \%$ dos casos nas articulações entre a $5^{\underline{a}}$ e $6^{\underline{a}}$ e $7^{\underline{a}}$ vértebras cervicais, ambas em 6,67\%.

$\mathrm{O} F d$ origina-se de filetes nervosos oriundos dos ramos ventrais do $5^{\circ}$ e $6^{\circ}$ Ec com C6 (Fig.1C), contribuindo com um filete maior em correspondência à articulação entre a $6^{\underline{a}}$ e $7^{\underline{a}}$ vértebras cervicais, formando um tronco que recebe o filete procedente do ramo ventral de $\mathrm{C} 5$, ao nível da 1aㅡ costela em 13,00\%.

Quando o Fd é composto por três raízes do $5^{\circ}, 6^{\circ}$ e $7^{\circ}$ nervos espinhais, cada um contribui com um filete nervoso (Fig.1D). A união dos ramos ventrais $\mathrm{C} 6$ e C7, constitui um tronco que ocorre entre a $6^{\underline{a}}$ e a $7^{\text {a }}$ vértebras cervicais, enquanto que o ramo oriundo de $\mathrm{C} 5$ une-se para compor o nervo frênico propriamente dito na altura da $1^{\underline{a}}$ costela, em $20,00 \%$.

Nos casos em que o Fd origina-se a partir dos ramos ventrais do $5^{\circ}, 6^{\circ}$ e $7^{\circ} \mathrm{E} \mathrm{Ec}$, com $\mathrm{C} 6$ contribuindo com dois filetes nervosos (Fig.1E), a união do curto filete de C6 com o filete de C7 ocorre entre a articulação da $6^{\underline{a}}$ e $7^{\underline{a}}$ vértebras cervicais; o tronco resultante une-se ao filete maior de $\mathrm{C} 6$ também em correspondência à articulação entre a $6^{\underline{a}}$ e $7^{\underline{a}}$ vértebras cervicais, enquanto que a contri- buição de C5 é incorporada ao nervo frênico direito propriamente dito, ao nível da $1^{\underline{a}}$ costela em $6,67 \%$ das amostras.

Nas análises estatísticas tanto o número de raízes formadoras $\left(\chi^{2}=0,292\right)$ quanto à altura da união das mesmas $\left(\chi^{2}=1,25\right)$ não revelou influência do sexo dos animais estudados.

\section{Nervo frênico esquerdo}

$\mathrm{O}$ nervo frênico esquerdo $(\mathrm{Fe})$ origina-se a partir de uma única raiz do ramo ventral do 6 o Ec em $6,67 \%$ e em $59,99 \%$ dos casos origina-se de duas raízes (tipo II).

Em $33,34 \%$ as raízes formadoras procedem dos ramos ventrais do $5^{\circ}$ e $6^{\circ}$ Ec, cada um fornecendo um único filete nervoso (Fig.2A). Enquanto que em 13,33\% originou-se do $6^{\circ}$ e $7^{\circ} \mathrm{Ec}$, em ambas as junções cada nervo contribuiu com um filamento nervoso (Fig.2B). Em 9,99\% das observações o nervo mencionado é constituído por duas raízes procedentes dos ramos $5^{\circ}$ e $6^{\circ}$ Ec, sendo que C6 colabora com dois filetes nervosos (Fig.2C).

Foi observada a ocorrência de $33,34 \%$ que o Fe origina-se a partir de 3 raízes (tipo III): $5^{\circ}$, $6^{\circ}$ e e $7^{\circ} \mathrm{Ec}$, cada um contribuindo com um único filete (Fig.2D). Em apenas $6,67 \%$ mostra-se procedente do ramo ventral do 6ํㅡ Ec (Fig.2E).

\section{Níveis de união dos filetes nervosos formadores do nervo frênico esquerdo}

Nas amostras em que o Fe forma-se a partir de dois ramos ventrais, $5^{\circ}$ e $6^{\circ}$, ou do $6^{\circ}$ e $7^{\circ}$ Ec (Fig.2A e $2 \mathrm{~B}$ ) cada um deles contribui com um único filete nervoso; a união destes ocorre na altura da $1^{\text {a }}$ costela em $35,31 \%$ e entre a $5^{\mathrm{a}}$ e $6^{\mathrm{a}}$ vértebras em $10,71 \%$.

Nas preparações em que o Fe é formado pelos ramos ventrais do $5^{\circ}$ e $6^{\circ} \mathrm{Ec}$, onde $\mathrm{C} 6$ contribui com dois filetes nervosos (Fig.2C), a união do filete curto com o maior processa-se em correspondência a articulação entre a $6^{\text {a }}$ e $7^{\underline{a}}$ vértebras cervicais, constituindo um tronco que recebe o filete nervoso proveniente do ramo ventral de $\mathrm{C} 5$ ao nível da $1^{\text {a }}$ costela em $7,14 \%$.

O Fe proveniente dos ramos ventrais do $5^{\circ}, 6^{\circ}$ e $7^{\circ} \mathrm{Ec}$, cada um contribuindo com um filete (Fig.2D), a união do ramo ventral do $\mathrm{C} 6 \mathrm{com} \mathrm{C} 7$, forma um tronco entre as $6^{\text {a }}$ e $7^{\text {a }}$ vértebras cervicais, enquanto que a união do ramo ventral de C5, compõe o nervo frênico esquerdo propriamente dito ao nível da $1^{\text {a }}$ costela, em $32,16 \%$.

$O$ teste $\chi^{2}$ não revelou influência do sexo do animal no número de raízes formadoras $\left(\chi^{2}=1,376\right)$, nem na localização de suas junções $\left(\chi^{2}=2,22\right)$.

\section{Formação dos nervos frênicos}

Quando analisados bilateralmente, mostram formação simétrica, provindo do mesmo número de raízes em $63,33 \%$, sendo o restante, $36,67 \%$ de formações assimétricas, simetria esta confirmada por meio do teste $\chi^{2}$ onde $\chi^{2}=10,24$ ao nível de significância de 5,00\%. Quanto ao nível de união destas raízes os resultados de- 


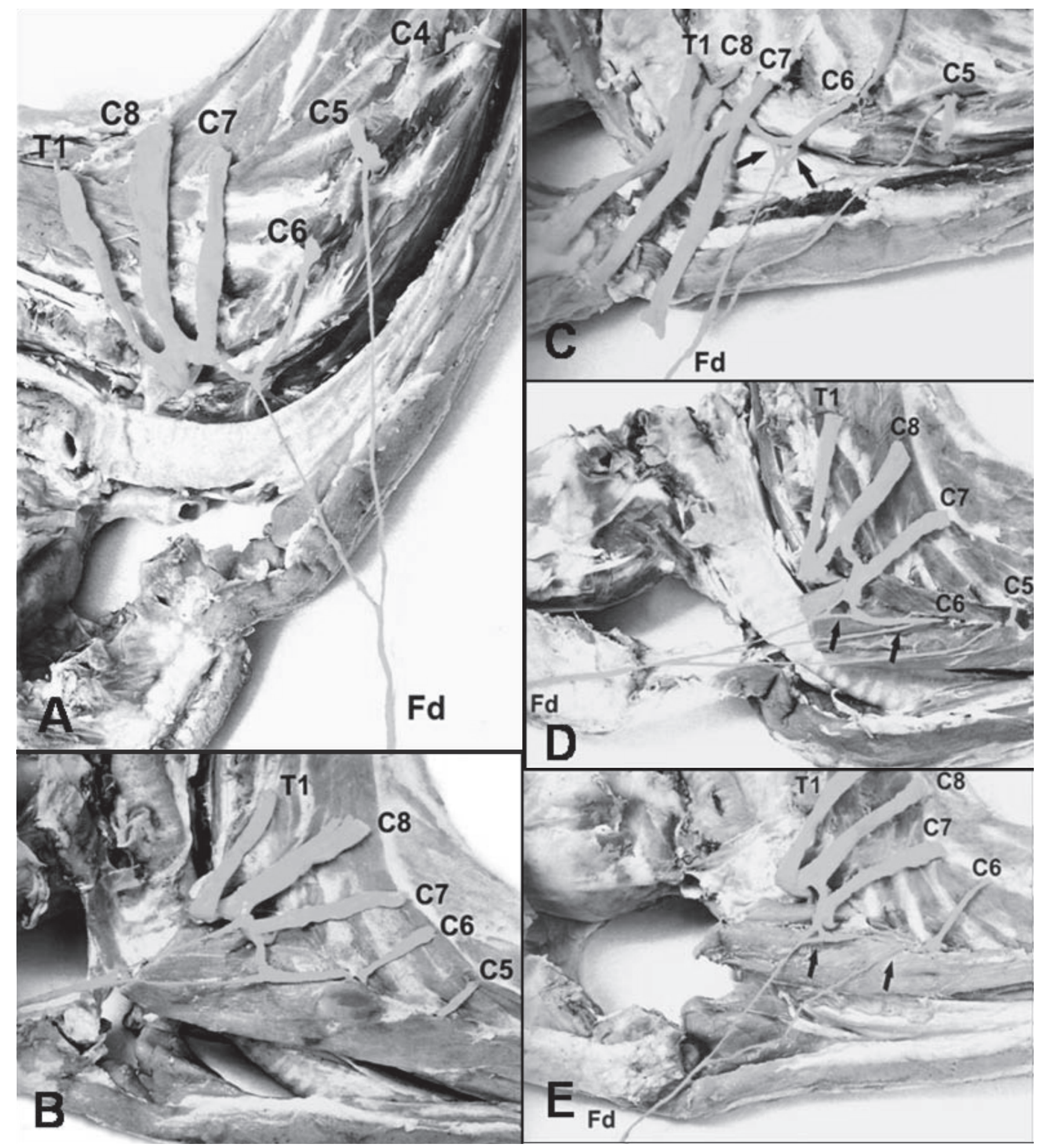

Fig.1. Terço distal da região cervical (vista lateral direita) de ovino da raça Santa Inês demonstrando as origens do nervo frênico: (A) de duas raízes procedentes dos ramos ventrais do $5^{\circ}(\mathrm{C} 5)$ e 6(C6) Nec; C5 e C6 contribuem com um único filete nervoso; (B) de duas raízes procedentes dos ramos ventrais do 6으 (C6) e 7ํㅡ (C7) Nec; C6 e C7 contribui com um único filete nervoso; (C) de duas raízes procedentes dos ramos ventrais do $5^{\circ}$ (C5) e 6은 (C6) Nec; C6 contribuí com dois filetes nervosos; (D) de três raízes procedentes dos ramos ventrais do 5 (C5), 6(C6) e $7^{\circ}$ (C7) Nec; C5 e C6 contribuem com um único filete nervoso e C6

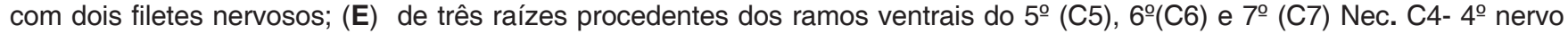

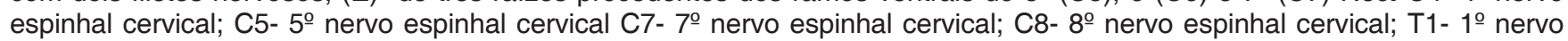
espinhal torácico. 




Fig.2. Terço distal da região cervical (vista lateral esquerda) de ovino da raça Santa Inês demonstrando as origens do nervo frênico: (A) de duas raízes procedentes dos ramos ventrais do 5 (C5) e 6으 (C6) do Ec; C5 e C6 contribuem com um único filete nervoso; dos ramos ventrais do 6은 (C6) e (C7) do Eec; (B) C6 e C7 contribuem com um único filete nervoso; (C) de duas raízes procedentes; de duas raízes procedentes dos ramos ventrais do 5 (C5) e 6o (C6); (D) C6 contribui com dois filetes nervosos; (E) três raízes procedentes dos ramos ventrais do 5으 (C5), 6으 (C6) e 7으 (C7) do Nec; cada um contribui com único filete nervoso; (F)

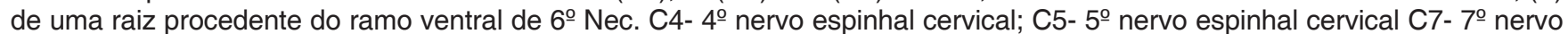
espinhal cervical; C8- 8 nervo espinhal cervical; T1- 1ำ nervo espinhal torácico. 
monstraram simetria entre os antímeros, $\chi^{2}=25,67 \mathrm{com}$ significância ao nível de rejeição de $5,00 \%$.

As raízes formadoras dos $\mathrm{F}$ correspondente a $\mathrm{C} 5$, quando presente, é mais longa, enquanto que $\mathrm{C} 7$ é mais curta e C6 é constante em todas as preparações.

\section{Ramos terminais dos nervos frênicos direito}

O Fd ramifica-se em ramos lombocostal e esternal em 40,00\% (Fig.3A); em 33,33\% dividi-se em ramos lombar, costal e esternal (Fig.3B); e separa-se em troncos lombocostal e costoesternal em 16,67\% (Fig.3C).

\section{Ramos terminais dos nervos frênicos esquerdo}

$\mathrm{O} F$ emite os ramos, lombar, costal e esternal em
$33,33 \%$ (Fig. 4 A); em $13,33 \%$ cedem os ramos lombar, costal e esternal concomitantemente (Fig.4B), em 26,68\% em ramos, lombar e costoesternal (Fig.4C) e em 20,00\% origina os troncos lombocostal e ramo esternal (Fig.4D)

\section{Ramos terminais dos nervos frênicos direito e esquerdo}

Os Fde são considerados juntos, originando ramos lombar, costal e esternal em 16,67\% (Fig.3B e 4B).

Em $16,67 \%$ o Fd fornece o tronco lombocostal e ramo esternal (Fig.3A) e o Fe, os ramos lombar, costal e esternal (Fig.4A).

Em 10,00\% o Fd resolve-se em ramos lombar, costal e esternal (Fig.3C) e o Fe, em ramo lombar e tronco costoesternal (Fig.4C); e os Fde imitem o tronco lombocostal

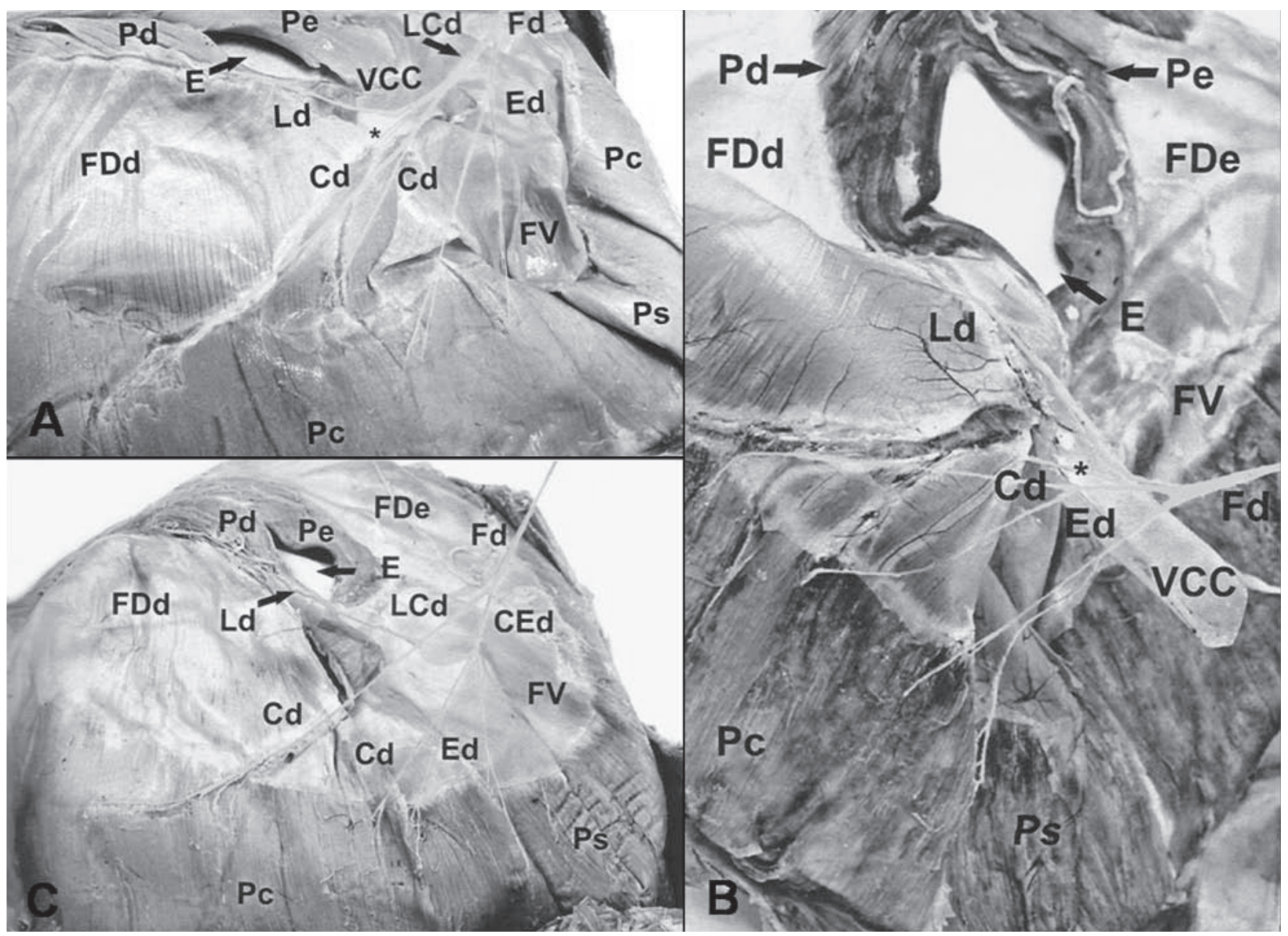

Fig.3. Diafragma (face torácica) de ovino da raça Santa Inês. (A) O nervo faríngeo direito (Fd) fornece os ramos lombocostal direito $(\mathrm{LCd})$ e ramo esternal direito (Ed). Do tronco lombocostal destacam-se o ramo lombar direito (Ld) e ramo costal direito (Cd). O ramo lombar direito (Ld) emite um filete nervoso $\left(^{*}\right)$ à veia cava caudal (VCC). (B) O nervo frênico direito (Fd) a divide-se em troncos lombocostal e partem o ramo lombar direito $(\mathrm{Ld})$ e o ramo costal direito $(\mathrm{Cd})$ e do tronco costoesternal segue o ramo costal direito $(\mathrm{Cd})$ e o ramo esternal direito $(\mathrm{Ed})$. (C) Nervo frênico $(\mathrm{Fd})$ a resolver-se em ramos lombar direito (Ld), costal direito $(\mathrm{Cd})$ e esternal direito $(\mathrm{Ed})$. O ramo lombar direito $(\mathrm{Ld})$ distribui-se ao pilar direito $(\mathrm{Pd})$; o ramo costal direito (Cd) alcança as regiões dorsal e ventral da pars costalis $(\mathrm{Pc})$, emitindo um filete nervoso $\left(^{*}\right)$ ao folíolo ventral (FV) enquanto o ramo esternal direito $(\mathrm{Ed})$ dirige-se à pars sternalis $(\mathrm{Ps})$ e à região ventral da pars costalis (Pc). FDd- folíolo dorsal direito; FDe- folíolo dorsal esquerdo; Pd- pilar direito; Pe- pilar esquerdo; E- hiato esofágico; FV- folíolo ventral; Pc- pars costalis; Ps- pars sternalis; Ehiato esofágico; VCC- veia cava caudal. 
e o ramo esternal (Fig.3B e 4B); e o Fd divide-se em tronco lombocostal e ramo esternal (Fig.3B) enquanto o $\mathrm{Fr}$ divide-se em ramo lombar e tronco esternal (Fig.4C).

O Fde ramificaram-se em ramos, lombar e costoester- nal (Fig.3C e 4B); e o Fd fornece os ramos, lombar costal e esternal (Fig.3C) e o esquerdo emitiu os troncos lombocostal e esternal (Fig.4D); o Fd dividi-se em troncos lombocostal e costoesternal (Fig.3B) e o Fe em ramos lom-

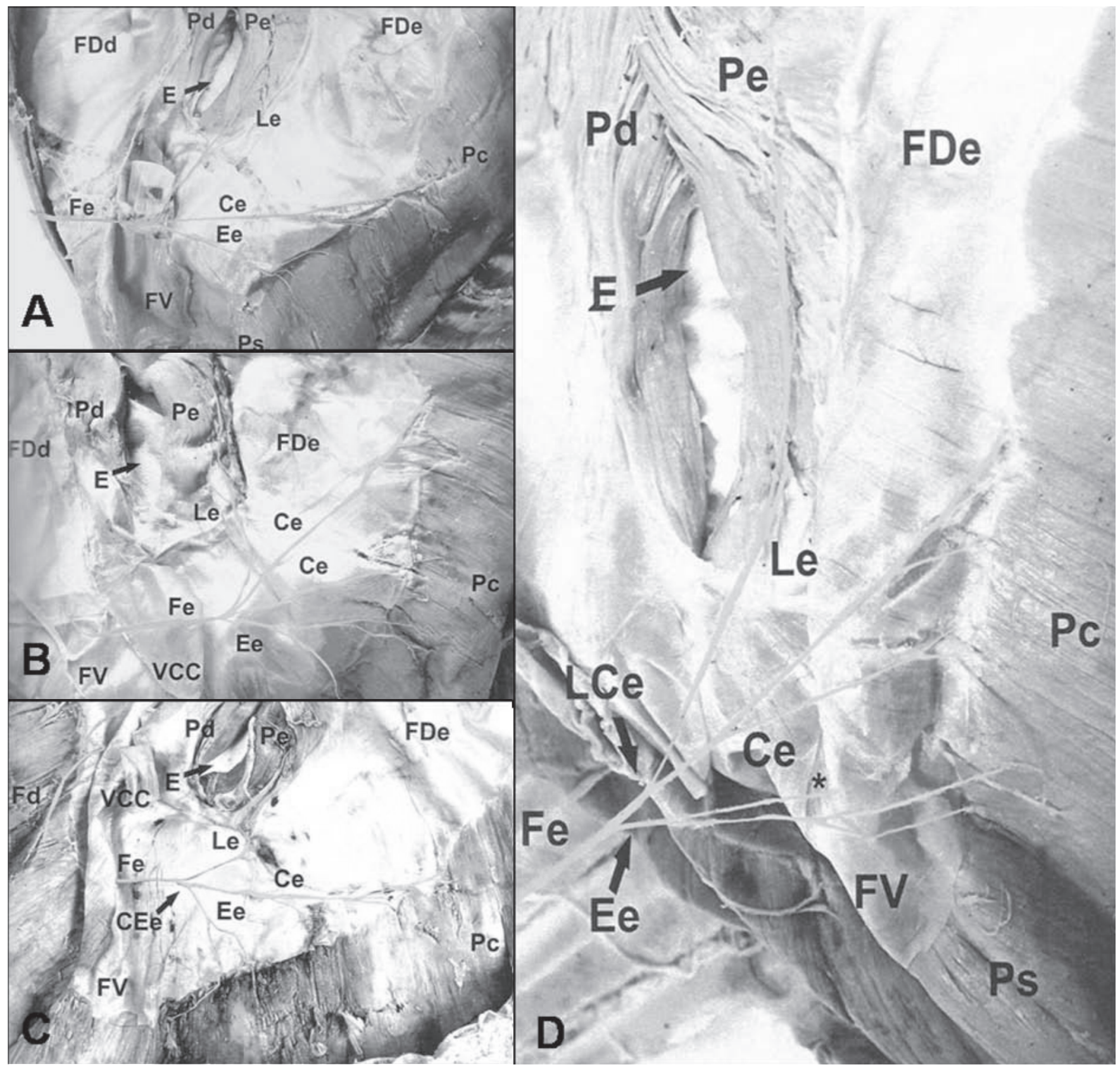

Fig.4. Diafragma (face torácica) de ovino da raça Santa Inês. (A) O nervo frênico esquerdo (Fe) emiti os ramos lombar esquerdo (Le), costal esquerdo (Ce) e esternal esquerdo (Ee). O ramo lombar esquerdo (Le) distribui-se no pilar esquerdo (Pe), o ramo costal esquerdo alcança as regiões dorsal e ventral da pars costalis $(\mathrm{Pc})$ e o ramo esternal esquerdo dirige-se à pars sternalis $(\mathrm{Ps})$ e à região ventral da pars costalis (Pc). (B) O nervo frênico esquerdo (Fe) dividi-se em ramo lombar esquerdo (Le) e o tronco costoesternal esquerdo (CEe) que deriva o ramo costal esquerdo (Ce) e o ramos esternal esquerdo (Ee). (C) $\mathrm{O}$ nervo frênico esquerdo (Fe) fornece o tronco lombocostal esquerdo (LCe) e o ramo lombar esquerdo (Le) e o ramo costal esquerdo (Ce). (D) O nervo frênico esquerdo (Fe) cede aos ramos lombar esquerdo (Le), costal esquerdo (Ce), e esternal esquerdo (Ee). FDd- folíolo dorsal direito; Fd- nervo frênico esquerdo; E- hiato esofágico; VCC- veia cava caudal; FDd- folíolo dorsal direito ; FDe- folíolo dorsal esquerdo; Pd- pilar esquerdo; Pe- pilar esquerdo; E- hiato esofágico; FV- folíolo ventral; Ps- pars sternalis; Pc- pars costalis. 


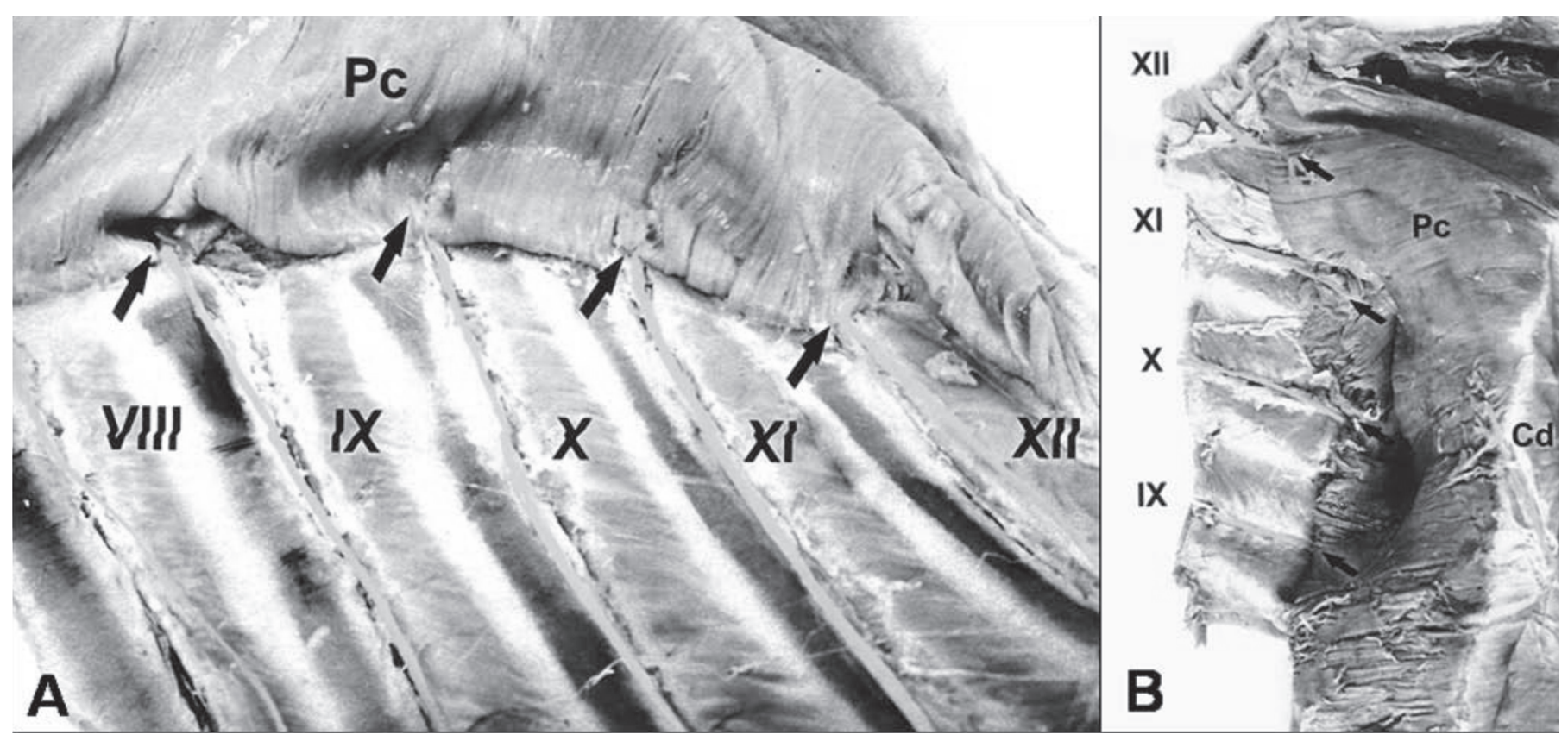

Fig.5. Diafragma (face torácica) de ovino da raça Santa Inês. (A) Contribuição dos nervos intercostais do VIII ao XII (setas); (B) XI ao XII setas em sua inervação; Pc- pars costalis; Cd- ramo costal direito do nervo frênico direito.

bar e costal e esternal (Fig.4B), 6,67\% em todos os casos.

\section{Distribuição dos ramos lombares, costais e esternais dos nervos frênicos direito \\ O ramo lombar do Fd distribuiu-se no pilar direito do} diafragma (pars lumbalis) emitindo um pequeno filete nervoso à veia cava caudal em $50,00 \%$. Em $46,67 \%$ dos casos o ramo lombar alcança o pilar direito do diafragma (pars lumbalis) (Fig.4A).

O ramo costal do Fd distribui-se nas regiões dorsal e ventral da pars costalis do diafragma em 56,67\% (Fig.4A). Em $20,00 \%$ os ramos se distribuíram nas regiões dorsal e ventral da pars costalis do diafragma, emitindo um filete nervoso no folíolo ventral em 16,67\% (Fig.4A).

O ramo esternal do Fd ramifica-se em 100,00\% dos casos na pars sternalis (antímero direito) e na região ventral da pars costalis (Fig.4A).

\section{Distribuição dos ramos lombares, costais e esternais dos nervos frênicos esquerdos}

O ramo lombar do Fe distribui-se $96,67 \%$ no pilar esquerdo do diafragma (pars lumbali) (Fig.4A).

O ramo costal do Fe ramifica-se em $70,00 \%$ nas regiões dorsal e ventral da pars costalis do diafragma e em $20,00 \%$ (Fig.4A) deparamos com 2 ramos distribuindo-se nas regiões dorsal e ventral da pars costalis. O ramo destinou-se as regiões dorsal e ventral da pars costalis e emitiu um filete nervoso para o folíolo ventral em 10,00\%.

O ramo esternal do $\mathrm{Fe}$ em $83,33 \%$ destina-se a pars sternalis e à região ventral da pars costalis do diafragma (Fig.4A), em 6,67\% distribui-se a pars esternalis do diafragma. Este expande-se pelas regiões ventral da pars esternalis e pela ventral da aorta da pars costalis, emitindo um filete nervoso ao folíolo ventral em $6,67 \%$.

Não foi observada anastomose nas amostras dos Fde. As divisões terminais dos $\mathrm{F}$ apresentaram simetria em $36,67 \%$ dos casos, exibindo o seguinte arranjo entre os antímeros: ramo lombar, costal e esternal (Fig.3C e 4B); tronco lombocostal e ramo esternal; ramo lombar e tronco costoesternal e troncos lombocostal e costoesternal.

No teste $\chi^{2}$, constatou-se não haver influência da variável sexo sobre a distribuição dos nervos frênicos.

\section{Participação de outros nervos na inervação do dia- fragma}

Em $63,33 \%$ houve contribuição dos nervos intercostais na inervação do diafragma do VIII ao XII (Fig.5A) e em $26,68 \%$ dos pares IX ao XII (Fig.5B) em ambos os antímeros.

Em 100,00\% os nervos intercostais destinam-se a contribuir na porção mais lateral da pars costalis em correspondência à linha de inserção costal do diafragma em curtos ramos que mergulham na porção periférica da região carnosa.

Não houve diferença pelo teste $\chi^{2}$ na participação dos nervos intercostais nos diferentes sexos, sendo $\chi^{2}=1,07$ à direita 0,927 à esquerda.

Os nervos lombares não participaram da inervação do diafragma em nenhuma das ocasiões estudadas.

\section{DISCUSSÃO}

Os resultados ora alcançados, mediante a dissecação e observação dos aludidos nervos, mostraram que os Fde originam a partir da união dos ramos ventrais do $5^{\circ}$ (C5) e 
6을 (C6) Ec. Esta mesma disposição é coerente com Ghoshal (1975) para ovinos e caprinos, sendo que a contribuição do $7^{\circ}(\mathrm{C} 7)$ é pequena ou ausente.

Com uma freqüência menor o $\mathrm{F}$ origina-se a partir dos ramos ventrais do $5^{\circ}, 6^{\circ}$ e $7^{\circ}$ Ec. Essa descrição é concordante com os tratadistas, Lesbre (1923), Zimmerl (1930), Ellenberger \& Baum (1932), Chauveau et al. (1950), Dobberstein \& Hoffman (1964), Schwarze \& Schroder (1972); e pelos autores especializados Locchi (1931) em Bradypus tridactylus, Lutnicki (1950) em carneiros; Girolla (1955) em bovinos. No entanto, há ocasiões em que os nervos originam-se dos ramos ventrais do $6^{\circ}$ e $7^{\circ}$ nervos cervicais, igualmente relatado nos estudos de bovinos de Souza et al. (1985), mas em discordância aos de búfalos de Bamel et al. (1970).

Não houve registro da eventual ocorrência de participação de filetes nervosos oriundos de outros Ec na formação dos $F$ que não 5ㅜㄴ 6ำ e $7^{\circ}$ Ec, em ovinos da raça Santa Inês. Porém Girrola (1955) para bovinos descreve a participação do $4^{\circ}$ Ec.

Segundo Locchi (1932) o volume dos nervos parafrênicos denuncia o principal nervo, e no caso de dois ou mais possuírem volumes semelhantes, o considerado principal será o que seguir o trajeto aceito como típico do nervo frênico comum. Em nosso estudo não foi possível a identificação da raiz principal por este conceito, já que todas apresentaram os volumes semelhantes; em contrapartida foi possível caracterizar a raiz de C5 como a mais longa e a de $\mathrm{C} 7$ como a mais curta; achados estes que coincidem com os estudos de Bamel (1970) em búfalos. Verificamos que C5 em concordância com Souza et al. (1985) se mostrou delgada ou ausente, e C6 é a principal raiz do $\mathrm{F}$ nos ovinos, devido ao fato deste constar em todas as observações deste estudo, e C5 e C7 são consideradas portanto nervos parafrênicos.

O Fd é originado de três raízes em menor ocorrência em nossos estudos, dados conflitantes aos de Neves (1968) e Souza et al. (1984) em bovinos, Miglino et al. (1982 e 1985) em caprinos e ovinos e Prada et al. (1987) em ovinos, que sugerem esta ocorrência como a segunda maior em seus estudos. Entretanto o Fd proveniente em trifurcação representou $1 / 3$ de nossos levantamentos, em concordância com Souza et al. $(1984,1987)$ e em desacordo ao estudo de Neves (1968) e Prada et al. (1987) em bovinos; Miglino et al. $(1982,1985)$ em caprinos, búfalos Jaffarabadi e ovinos Ideal e Souza et al. (1984) em bovinos Nelore. Em poucas oportunidades o mesmo nervo dividiu-se em ramos lombar, costal e esternal, assim como Prada et al. (1987) em seus experimentos.

O Fe divide-se em ramo lombar e tronco costoesternal em 1/4 de nossos achados, dados semelhantes foram relatados por Ferreira et al. (1973) em ovinos Corriedale, Miglino et al. (1985) em ovinos Ideal e Prada et al. (1987) em ovinos deslanados, em contrapartida Pancrazi (1925), Girola (1955), Neves (1968), Miglino et al. (1982, 1985), Souza et al. (1984) e Tocantins Neto (1985) encontraram esta divisão em maior número em seus relatos. Em nos- sos resultados $1 / 5$ das divisões do Fe resulta no tronco lombocostal e no ramo esternal, valores maiores foram descritos por Ferreira et al. (1973) respectivamente em ovinos Corriedale, Ferreira et al. (1981) em ovinos deslanados, números inferiores foram evidenciados nos estudos de Neves (1968) em fetos bovinos, Miglino et al. (1982) e em caprinos.

O par do nervo frênico apresenta comportamento simétrico em 1/3 dos casos; desta forma descrevemos a divisão por trifurcação resultando em ramos lombar, costal e esternal, de acordo com o descrito por Miglino et al. (1982, 1985) em caprinos e ovinos Ideal, e por Prada et al. (1987) em ovinos deslanados, porém em menor escala.

Registramos a bifurcação à direita em tronco lombocostal e ramo esternal, concordando com os autores Ferreira et al. (1973) em ovinos Corriedale, Miglino et al. (1985) em búfalos Jaffarabadi e Prada et al. (1987) em ovinos deslanados. Em menor freqüência está dividido em ramos lombocostal e esternal; tronco lombocostal e costoesternal (não mencionada em nenhum dos trabaIhos consultados); e a divisão em ramo lombar e tronco costoesternal, sendo esses encontrados em maior número nos trabalhos de Pancrazi (1925), Girolla (1955), Neves (1968) e Souza et al. (1984) em bovinos, de Miglino et al. $(1982,1985)$ em caprinos e ovinos Ideal e de Tocantins Neto (1985) em búfalos Murrah.

Em se tratando da bifurcação à esquerda, a ordem de importância dos eventos ocorre primeiramente com a divisão em ramos lombocostal e esternal; ramo lombar e tronco costoesternal, tronco lombocostal e ramo esternal. Em menor escala as divisões em ramos lombar, costal e esternal; tronco lombocostal e costoesternal; e ramos lombar, costal e tronco costoesternal.

Os nossos resultados sobre a inervação do diafragma de ovinos da raça Santa Inês diferem daqueles apresentados por Zimmerl (1909), Andrei (1928), Ghoshal (1975), os quais afirmam que os nervos frênicos são as principais, e provavelmente únicas fontes de inervação para o diafragma em alguns mamíferos

Ao examinarmos as descrições contidas nos tratados de Anatomia Veterinária, concernentes à divisão terminal dos F, verificamos que Zimmerl (1909), Lesbre (1923), Ellenberger \& Baum (1932), comentam, que os $F$ chegam ao centro frênico e se distribuem à porção carnosa. Entretanto os ramos dos $\mathrm{F}$ inervam em maior escala a parte muscular do diafragma, os folíolos dorsal e ventral e a parede da veia cava caudal, fatos encontrados nos estudos de Miglino et al. (1982, 1985, 1993) em caprinos, búfalos Jafarabadi e veados, Souza et al. (1984) em bovinos Nelore, Tocantins Neto (1985) em búfalos Murrah, e Prada et al. (1987) em ovinos deslanados. Em contrapartida, nas pesquisas de Pancrazi (1925) em bovinos, Lutinicki (1950) em ovinos, Girolla (1955) em bovinos, Neves (1968) em fetos bovinos, Bamel et al. (1970) em búfalos, Miglino (1985) em ovinos Ideal, afirmam que os F se distribuem apenas na porção muscular do diafragma.

Mia (1973) para zebuínos descreve que o diafragma é 
inervado por fibras derivadas de nervos intercostais. Porém Andrei (1928); citam que somente as fibras sensitivas desses nervos alcançam o diafragma. Cavalié (1898) e Dyce, (2004) complementam que as referentes fibras são motoras e possuem origem nos nervos intercostais, também relacionado ao diafragma de gatos (Chou \& Davenport 2005). Rosenblueth et al. (1961) relata que a participação dos nervos intercostais está relacionada a ações não respiratórias, como tosse, vômito, defecação, parto etc. Os resultados sugerem que os nervos intercostais, e especialmente do $7^{\circ}$ ao $9^{\circ}$ são importantes vias eferentes para algumas dessas ações ou reflexos. Por fim, os nervos intercostais devem ser lembrados em relação a sua ação entre diafragma e nervo frênico descritos em catetos por Moura et al. (2007) e suas funções básicas na manutenção da homeostase animal e mecanismos respiratórios, além de ressaltarmos a importância de pesquisas básicas morfofisiológicas para embasar estudos visando à regeneração nervosa (Inoe et al. 2007).

\section{CONCLUSÕES}

O diafragma dos ovinos da raça Santa Inês é inervado pelos nervos frênicos direito e esquerdo, sendo o C6 seu principal fornecedor, e pelos nervos intercostais do VII ao XII pares, do IX ao XII pares e do VIII ao XII pares.

Não é observada a presença de anastomoses homo e/ ou heterolaterais entre os ramos terminais dos nervos frênicos direito e esquerdo.

Não há interferência na variável sexo sobre o comportamento dos nervos frênicos no tocante as suas origens e distribuições no diafragma de ovinos da raça Santa Inês, tudo ocorrendo pelo acaso.

\section{REFERÊNCIAS}

Amorim Júnior A.A. 1988. Ramificação e distribuição dos nervos frênicos no diafragma de jumentos nordestinos. Dissertação de Mestrado em Anatomia dos Animais Domésticos, Faculdade de Medicina Veterinária e Zootecnia, Universidade de São Paulo. 63p.

Andrei O. 1928. Sulle alterazioni anatomiche del diafragma che susseguono adeserei del nervo frênico. Arch. Ital. Cirur. 21:313-328.

Arey L.B. 1964. Mesenterios y celoma, p.231-232. In. (ed.), Anatomia del Desarrolo: tratado y manual de laboratório. Vasquez, Buenos Aires.

Bamel S.S., Dhingra L.D. \& Singh Y. 1970. The pherenic nerve of the buffalo (Bos bubalis). Philippine J. Vet. Med. 10:36-41.

Bertelli D. 1933. Distribuizone dei nerve frenice nei diaframma dei mammiferi. Arch. Ital. Anatom. Embriol. 32:110-148.

Cavalié C. 1898. (Cit. Rosenblueth et al. 1961)

Chauveau A., Arloing S. \& Lesbre F.X. 1950. Appareil de innervation, p.552-553. In: Chauveau A., Arloing S. \& Lesbre F. (ed.), Traité d'Anatomie Comparée des Animaux Domestiques. Vol.2. $5^{\text {ième }}$ ed. Bailliére, Paris.

Chou Y.-L. \& Davenport P.W. 2005. Phrenic nerve afferents elicited cord dorsum potential in the cat cervical spinal cord. BMC Physiology $5: 7$.

Conde R. 1957. Estudo anatômico sobre a distribuição dos nervos frênicos no músculo diafragma de Canis familiaris. Arqs Esc. Sup. Vet., 10:329-365.
Dobberstein J. \& Hoffman G. 1964. Nervensystem, p.165. In: Dobberstein J. \& Hoffman G. (ed.), Lehrbuch der Vergleichenden Anatomie der Haustiere. Vol.3. S. Hirzel, Leipzig.

Dyce K.M., Sack W.O. \& Wensing C.J.G. 2004. Tratado de Anatomia Veterinária. $3^{\underline{a}}$ ed. Guanabara Koogan, Rio de Janeiro, p.307-308.

Ellenberger W. \& Baum H. 1932. Nervensystem, p.894-895. In: (ed.), Handbuch der Vergleichenden Anatomie der Haustiere. Verlag J. Springer, Berlin.

Farias M.M.M.D., Wenceslau C.V., Passos J., Teixeira D.G., Araújo K.P.C., Ambrósio C.E., Martins D.S. \& Prada I.L.S. 2007. Behavior of the glossopharyngeal and vagus nerves in the retropharyngeal region of sheep: apparent origin in cranium, course, branching and distribution. Pesq. Vet. Bras. 27:115-123.

Ferreira N., Fernandes Filho A. \& D'Errico A. 1973. Distribuição dos nervos frênicos no diafragma em carneiros da raça Corriedale. Anais da Jornada Científica da Faculdade de Ciências Médicas e Biológicas, Botucatu, p.263.

Ferreira N., D Errico A.A., Prada I.L.S. \& Sogorb S.F. 1981. Distribuição dos nervos frênicos no diafragma do ratão do banhado (Miocastos coypus). Anais Congr. Bras. Anatomia, Belo Horizonte, p.10213.

Getty R. 1986. Sisson/Grossman Anatomia dos Animais Domésticos. Vol.2. 5 ${ }^{\mathrm{a}}$ ed. Guanabara Koogan, Rio de Janeiro, p.1607-1617.

König H.E. \& Liebich H.G. 2004. Anatomia dos Animais Domésticos: texto e atlas colorido. Artmed, Porto Alegre, p.252.

Ghoshal N.G. 1975. Nervos espinhais, p.1052-1055. In: Getty R. (ed.), Anatomia dos Animais Domésticos. 5 ${ }^{\mathrm{a}}$ ed. Guanabara Koogan, Rio de Janeiro.

Girolla W. 1955. Der Nervus phrenicus des Rindes: seine Morphologie, Topik, Innervations- und Functionsaufgaben. Tese de Doutorado em Medicina Veterinária, Tierärztliche Hochschule Wien. 44p.

González y Garcia J. \& Conzález Alvarez R. 1949. Sistema muscular, p.319. In: González y Garcia J. \& Conzález Alvarez R. (ed.), Anatomia Comparada de los Animales Domesticos. 6 ${ }^{\underline{a}}$ ed. Juan Puevo, Madrid.

Inoe A.P., Pereira C.P., Stopiglia A.J. \& Da-Silva C.F. 2007 Pharmacological immunomodulation enhances peripheral nerve regeneration. Pesq. Vet. Bras. 27(9):363-369.

International Committe on Veterinary Gross Anatomical Nomenclature 1994. Nomina Anatomica Veterinaria. 4th ed. Zürich.

Leite E.R. 2000. Ovinocaprinocultura no Nordeste: organização e crescimento. A Tarde, Salvador, Rural, 24 abril, p.6.

Lesbre F.X. 1923. Appareil de innervation, p.668-669. In : Lesbre F.X. (ed.), Précis d' Anatomie Comparée de Animaux Domestiques. Vol.2. J.B. Bailliére, Paris.

Locchi R. 1931. Observações sobre o musculus diaphragma no Bradyps tridactylus. Annaes Fac. Med. São Paulo 6:3-22.

Locchi R. 1932. Quelques observations sur le "paraphrénique" nerve. Annaes Fac. Med. São Paulo 8:3-36.

Lutnicki W. 1950. The phrenic nerve in the sheep. Annales Universitatis Mariae Curie, Sklodowska, 5:47-69.

Machado T.M.M. 1999. Comportamento reprodutivo de ovinos deslanados no municípo de Uberlândia, Minas Gerais. Revta Bras. Reprod. Anim. 23:190.

Mia A. 1973. The innervation of the diaphragm in zebu cattle (Bos indicus). Bangladesh Vet. J. 1:29-32.

Miglino M.A. 1982. Divisão e distribuição dos nervos frênicos no músculo diafragma em caprinos (Capra hircus Linnaeus, 1758). Dissertação de Mestrado em Anatomia dos Animais Domésticos, Faculdade de Medicina Veterinária e Zootecnia, Universidade de São Paulo. 40p.

Miglino M.A., Souza W.M., Pereira J.G.L. \& Carvalhal R. 1985. Ramificação e distribuição dos nervos frênicos no diafragma de ovinos da raça Ideal. Anais 14ํㅡㄹ. Congr. Bras. Anatomia, Vitória, p.109.

Miglino M.A., Souza W.M., Carvalhal R. \& Didio L.J.A. 1993. Morfologia 
e inervação do diafragma de veados (Manzana americana, Manzana simplicicornis e Blastoceros bezoarticus). Braz. J. Vet. Res. Anim. Sci. 30(Suppl.):195-203.

Moreira P.R.R., Guimarães G.C., Machado M.R.F., Santos A.L.Q., Gerbasi S.H.B. \& Miglino M.A. 2007. Ramificação e distribuição dos nervos frênicos no músculo diafragma do gato doméstico. Braz. J. Vet. Res. Anim. Sci. 44(4):290-296.

Moura C.E.B., Albuquerque J.F.G., Magalhães M.S., Silva N.B.S., Oliveira M.F. \& Papa P.C. 2007. Análise comparativa da origem do plexo branquial de catetos (Tayassu tajacu). Pesq. Vet. Bras. 27(9):357362

Neves I. 1968. Estudo anatômico da distribuição dos nervos frênicos no músculo diafragma de bovinos (fetos). Veterinária, Rio de J., 21:2945.

Nickel R., Schummer A. \& Seiferle E. 1977. Muskeln des Stammes, p.332-334. In: (ed.), Lehrbuch der Anatomie der Haustiere. Bd.1. Verlag Paul Parey, Berlin.

Pancrazi G. 1925. Sulia distribuizone del nervo frenice nel diafragma dei mamiferi. Atti Del Reale Istituto Veneto de Scienze 85:345-347.

Prada I.L.S., Amorim Jr A.A., Miglino M.A. \& Souza W.M. 1987. Ramificações e distribuição dos nervos frênicos no diafragma em ovinos deslanados. Comunicações Científicas da Faculdade de Medicina Veterinária e Zootecnia, Universidade de São Paulo,11:145-146.

Riet-Correa F., Riet-Correa G. \& Schild A.L. 2002. Importância do exame clínico para o diagnóstico das enfermidades do sistema nervoso em ruminantes e eqüídeos. Pesq. Vet. Bras. 22:161-168.
Rosenblueth A., Alanís J. \& Pilar G. 1961. The accessory motor innervation of the diaphragm. Arch. Int. Physiol. Biochem. 69:19-25.

Schwarze E.O. \& Schroder L. 1972. Nervios cervicales, p.63-66. In: (ed.), Compendio de Anatomia Veterinária. Vol.4. Acribia, Zaragoza.

Souza W.M., Miglino M.A., Machado C.R. \& Carvalhal R. 1985. Considerações sobre os níveis de origem dos nervos frênicos em bovinos azebuados. Arqs Biol. Tecnol., Curitiba, 28:619-624.

Souza W.M., Miglino M.A., Prada I.L.S. \& Souza N. 1987. Sobre a ramificação e distribuição dos nervos frênicos direito e esquerdo no diafragma, em suínos, (Sus scrofa domesticus, L. 1758) da raça Landrace. Ars Vet. 3:171-178.

Souza W.M., Pereira J.G.L. \& Albuquerque J.F.G. 1984. Contribution to the study of diaphragm innervation in Nelore bovines. Anat. Anz. 155:317-323.

Tocantins Neto A.A. 1985. Divisão e distribuição dos nervos frênicos no diafragma de búfalos (Bubalus bubalis, Linnaeus, 1758) da raça Murrah. Dissertação de Mestrado em Anatomia dos Animais Domésticos, Faculdade de Medicina Veterinária e Zootecnia, Universidade de São Paulo, SP. 74p.

Zimmerl U. 1909. Sistema nervoso, p.228-229. In: Bossi V., Caradonna G.B., Spampani G., Varaldi L. \& Zimmerl U. (ed.), Trattato di Anatomia Veterinária. Vol.3. Francesco Vallardi, Milano.

Zimmerl U. 1930. Apparecchio nervoso, p.476. In: Bruni A.C., Caradonna G.B., Mannu A., Preziuso L. \& Zimmerl U. (ed.), Trattato di Anatomia Veterinaria. Vol.3. Francesco Vallardi, Milano. 